\title{
RADIOTHERAPY CAN BE A CRUSADER FOR CHEMOTHERAPY-RESISTANT ISOLATED CNS RELAPSE IN SYSTEMIC NON-HODGKIN LYMPHOMA- A CASE REPORT
}

Kannan Periasamy1, Parthasarathy Vedasoundaram², Shyama Prem Sudha ${ }^{3}$

${ }^{1}$ Senior Resident, Radiation Oncology, Jawaharlal Institute of Postgraduate Medical Education and Research (JIPMER).

${ }^{2}$ Additional Professor and HOD, Radiation Oncology, Jawaharlal Institute of Postgraduate Medical Education and Research (JIPMER). ${ }^{3}$ Additional Professor, Radiation Oncology, Jawaharlal Institute of Postgraduate Medical Education and Research (JIPMER).

HOW TO CITE THIS ARTICLE: Periasamy K, Vedasoundaram P, Sudha SP. Radiotherapy can be a crusader for chemotherapyresistant isolated CNS relapse in systemic non-Hodgkin lymphoma- A case report. J. Evolution Med. Dent. Sci. 2017;6(54):41154117, DOI: $10.14260 /$ Jemds/2017/890

\section{PRESENTATION OF CASE}

A 60-year-old male presented with swelling in the left submandibular region and cervical region. He was investigated and was found to have high-grade B-cell NonHodgkin Lymphoma in 2010. He received six cycles of RCHOP (Rituximab, cyclophosphamide, doxorubicin, vincristine, prednisone) chemotherapy. He was symptomfree till 2015. In February 2015, he presented with complaints of severe headache and signs of increased intracranial tension. Contrast-enhanced computed tomography revealed homogeneously enhancing lobulated mass lesions, three in number, with small central ill-defined hypoattenuating areas noted in right supratentorial region predominantly in the subependymal regions along the right lateral ventricle around the frontal horn, and occipital horn with near total obliteration of right lateral ventricle and also in the subcortical white matter region of right parietal lobe [Figure 1]. He had no evidence of significant lymphadenopathy in the neck, thorax, abdomen, and pelvis.

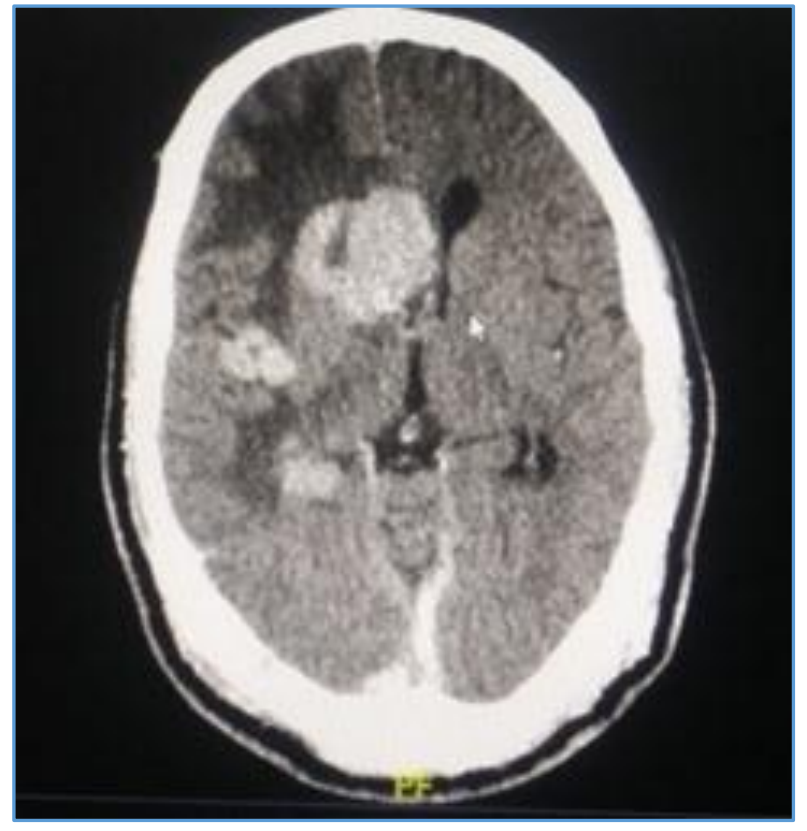

Figure 1. CECT Showing Enhancing Lesions

Financial or Other, Competing Interest: None.

Submission 13-03-2017, Peer Review 23-06-2017,

Acceptance 29-06-2017, Published 06-07-2017.

Corresponding Author:

Parthasarathy Vedasoundaram,

Additional Professor and HOD,

Department of Radiation Oncology,

Regional Cancer Centre, JIPMER.

E-mail:dr_patchu2003@yahoo.co.in

DOI: $10.14260 /$ jemds $/ 2017 / 890$

\section{(c) (i) $(3)$}

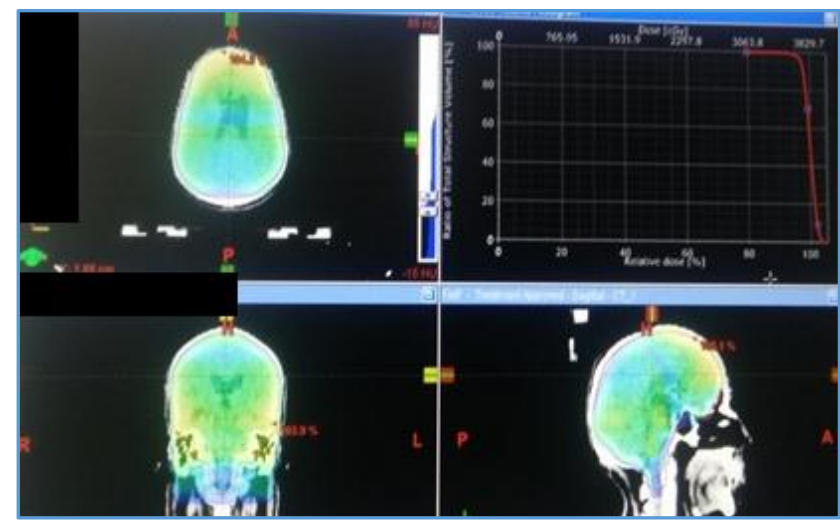

Figure 2. Whole Brain Radiotherapy-dose Distribution

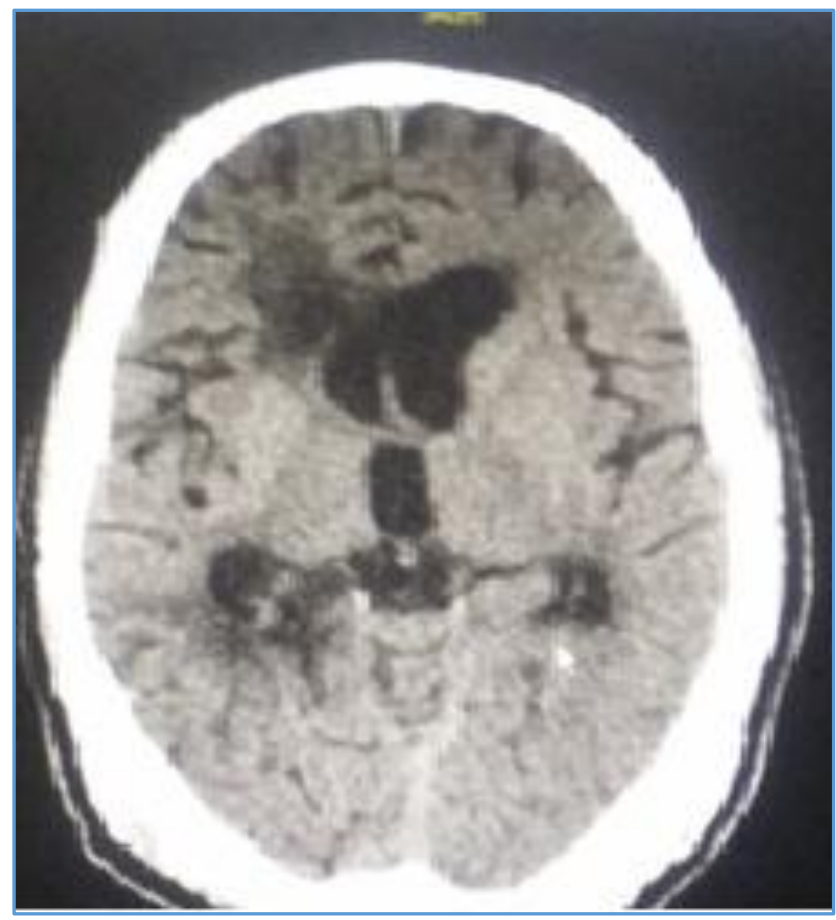

Figure 3. Complete Disappearance of Lesion after Radiotherapy

\section{CLINICAL DIAGNOSIS}

Stereotactic biopsy from the lesion confirmed Non-Hodgkin lymphoma. Cerebrospinal fluid cytology was negative. Bone marrow biopsy revealed no evidence of infiltration by lymphoma. The patient was diagnosed to have isolated CNS relapse and was treated with five cycles of chemotherapy with R-MPV (Rituximab, methotrexate, procarbazine, and vincristine). Post-chemotherapy imaging showed progressive disease. So, the patient was not considered for bone marrow 
transplantation. He was treated with whole brain radiotherapy of 40 Gy in 20 fractions by CRT technique in October 2015 [Figure 2].

Post-radiotherapy CECT was done in November 2015 which showed complete resolution of the enhancing mass noted in the previous scan. It also showed ill-defined hypodensity in a right periventricular region adjacent to the frontal horn, trigone and occipital horns of right lateral ventricle causing mild effacement of the frontal horn suggestive of post radiation changes [Figure 3]. MRI in January 2016 showed no contrast enhancing lesion and demonstrated only posttreatment changes. PET-CT did in January 2016 also confirmed no evidence of metabolically active disease anywhere in the body.

\section{DISCUSSION OF MANAGEMENT}

Isolated central nervous system [CNS] relapse involving brain parenchyma in a patient with systemic non-Hodgkin lymphoma [NHL] is not uncommon. About $2 \%$ to $4 \%$ of systemic non-Hodgkin lymphoma relapses in the brain. Longterm survival is possible with systemic methotrexate based combination chemotherapy in isolated CNS relapse in nonHodgkin lymphoma, and it is considered the current standard of care. Whole brain radiotherapy is not a preferred modality in older individuals due to its delayed neurotoxicity. However, in patients with disease not responding to chemotherapy, whole brain radiotherapy needs to be considered. One of the patients who progressed and deteriorated with chemotherapy was treated with whole brain radiotherapy. Radiotherapy was the messiah for this patient, and he had a complete recovery with whole brain RT.

There are three patterns of central nervous system involvement in non-Hodgkin lymphoma; primary, secondary and isolated CNS relapses. In primary CNS lymphoma, the disease is limited to the brain parenchyma, leptomeninges, eyes, and the spinal cord ${ }^{1}$; whereas in secondary CNS lymphoma, there is concomitant systemic and CNS involvement, often involving the leptomeninges. Isolated CNS relapse is defined as involvement of CNS in a known systemic non-Hodgkin lymphoma cases but with no evidence of systemic disease.

Central nervous system [CNS] relapse with systemic nonHodgkin lymphoma may involve the brain parenchyma, spinal cord, leptomeninges, or eyes. Central nervous system involvement may be part of disease progression or as a recurrence of systemic disease. ${ }^{2}$ Isolated CNS relapse with systemic NHL with no evidence of disease outside the central nervous system is rare, and it occurs in approximately $2 \%$ to $4 \%$ of patients. 3,4 There are no standard guidelines for the management of isolated CNS relapse case. In general, pathologic documentation by stereotactic biopsy is mandatory when imaging studies suggest Non-Hodgkin lymphoma in brain parenchyma. ${ }^{5}$ In our patient, stereotactic biopsy revealed Non-Hodgkin lymphoma confirmed by immunohistochemistry markers.

Systemic high-dose methotrexate based combination chemotherapy with or without whole brain radiotherapy is recommended for any CNS lymphoma.6,7,8,9 The role of radiotherapy in the management of CNS lymphoma is limited by insufficient local control and delayed neurotoxicity in terms of gait and memory disturbances. Nelson et al ${ }^{10}$ studied whole brain radiation therapy alone in the management of primary CNS lymphoma. The dose delivered was 36-40 Gy. The overall response rate was $90 \%$ but a median overall survival was only 11.6 months and $60 \%$ of patients developed progression of lymphoma within the irradiated field. Data suggest that high-dose chemotherapy with autologous stem cell transplant is feasible and efficient in patients with CNS relapses. ${ }^{11}$ In the study patient, high dose Methotrexate-based chemotherapy showed resistance, and in fact, the disease progressed on treatment. Performance status deteriorated further due to high dose chemotherapy schedule. So the patient was not considered for any further intensive chemotherapy and stem cell transplantation. Once the patient was stabilised, he was considered for whole brain radiotherapy to a total dose of 40 Gy in 20 fractions. Radiotherapy period was uneventful. Follow-up contrastenhanced CT and MRI showed no evidence of disease in the brain parenchyma.

PET-CT was done three months post-radiotherapy, and it showed no signs of disease anywhere in the body. Now the patient is on regular follow-up. Although longer follow-up is required to establish the role of WBRT, our patient has a disease-free interval of 10 months till now. WBRT should be considered in patients not responding to standard chemotherapy.

\section{Conclusion}

Isolated CNS relapse in Non-Hodgkin lymphoma is quite rare. High-dose Methotrexate-based chemotherapy forms the standard of care for most cases of CNS relapses, but whole brain radiotherapy can still be a messiah for resistant cases. Complete response is possible with whole brain radiotherapy. However, the duration of sustained response can be ascertained only on long term follow-up.

\section{FINAL DIAGNOSIS}

Stereotactic biopsy revealed Non-Hodgkin lymphoma confirmed by Immunohistochemistry markers.

\section{REFERENCES}

[1] Hochberg FH, Miller DC. Primary central nervous system lymphoma. J Neurosurg 1988;68(6):835-53.

[2] Doolittle ND, Abrey LE, Shenkier TN, et al. Brain parenchyma involvement as isolated central nervous system relapse of systemic non-Hodgkin lymphoma: an international primary CNS lymphoma collaborative group report. Blood 2008;111(3):1085-93.

[3] Bernstein SH, Unger JM, Leblanc $M$, et al. Natural history of CNS relapse in patients with aggressive nonHodgkin's lymphoma: a 20-year follow-up analysis of SWOG 8516-the southwest oncology group. J Clin Oncol 2009;27(1):114-9.

[4] Feugier P, Virion JM, Tilly H, et al. Incidence and risk factors for central nervous system occurrence in elderly patients with diffuse large-B-cell lymphoma: influence of rituximab. Ann Oncol 2004;15(1):129-33.

[5] Grier J, Batchelor T. Metastatic neurologic complications of non-Hodgkin's lymphoma. Curr Oncol Rep 2005;7(1):55-60. 
[6] DeAngelis LM, Yahalom J, Thaler HT, et al. Combined modality therapy for primary CNS lymphoma. J Clin Oncol 1992;10(4):635-43.

[7] Glass J, Gruber ML, Cher L, et al. Preirradiation methotrexate chemotherapy of primary central nervous system lymphoma: long-term outcome. J Neurosurg 1994;81(2):188-95.

[8] Thiel E, Korfel A, Martus P, et al. High-dose methotrexate with or without whole brain radiotherapy for primary CNS lymphoma (G-PCNSLSG-1): a phase 3, randomized, non-inferiority trial. Lancet Oncol 2010;11(11):1036-47.

[9] Bokstein F, Lossos A, Lossos IS, et al. Central nervous system relapse of systemic non-Hodgkin's lymphoma: results of treatment based on high-dose methotrexate combination chemotherapy. Leuk Lymphoma 2002;43(3):587-93.
[10] Nelson DF, Martz KL, Bonner H, et al. Non-Hodgkin's lymphoma of the brain: can high dose, large volume radiation therapy improve survival? Report on a prospective trial by the radiation therapy oncology group (RTOG): RTOG 8315. Int J Radiat Oncol Biol Phys 1992;23(1):9-17.

[11] Soussain C, Hoang-Xuan K, Taillandier L, et al. Intensive chemotherapy followed by hematopoietic stem-cell rescue for refractory and recurrent primary CNS and intraocular lymphoma: société française de greffe de moëlle osseuse-thérapie cellulaire. J Clin Oncol 2008;26(15):2512-8. 